\title{
MODEL-BASED PRODUCT CONFIGURATION OF HIGH VARIETY PRODUCT PORTFOLIOS
}

\author{
C. Wyrwich ${ }^{凶}$, G. Jacobs, J. Siebrecht and C. Konrad \\ RWTH Aachen University, Germany \\ $\triangle$ christian.wyrwich@imse.rwth-aachen.de
}

\begin{abstract}
Facing a rising competitive pressure, manufactures create advantages when they are able to offer customer-specific products to the conditions of a mass production article. Traditional configurators support the creation of personalized products from the elements of a modular product system, but are based on a pre-defined set of rules. The model based approach changes the environment of configuration from static configuration rules to the dependencies defined within the product's system model. So, by regarding target quantities of the user, the configurator identifies the optimal variant.
\end{abstract}

Keywords: model-based engineering, configuration management, design knowledge, optimal product variant

\section{Motivation and research objective}

Today, companies are facing increasing competitive pressure. As a result of the change from a seller's to a buyer's market, one key success factor for manufactures is their ability to offer customer-specific products with the quality, in the delivery time and the price of a mass-produced product (Arnoscht et al., 2010). In this area of conflict, a systematic product design portrays a decisive aspect for the company's competitiveness (Riesener, 2015; Schuh et al., 2007). As a part of the mass customization concept and an essential link to the customer, product configurators offer the possibility to assemble a personalized product (Stormer, 2007). However, current configurators (view Figure 1) are often designed as encapsulated software solutions, which can only be adapted insufficiently to a modified market situation. The product characteristics have to be determined by the user, until a final preplanned technical solution remains. So, regardless whether a product feature portrays a differentiating characteristic for the customer, a specific option has to be chosen to complete the configuration.

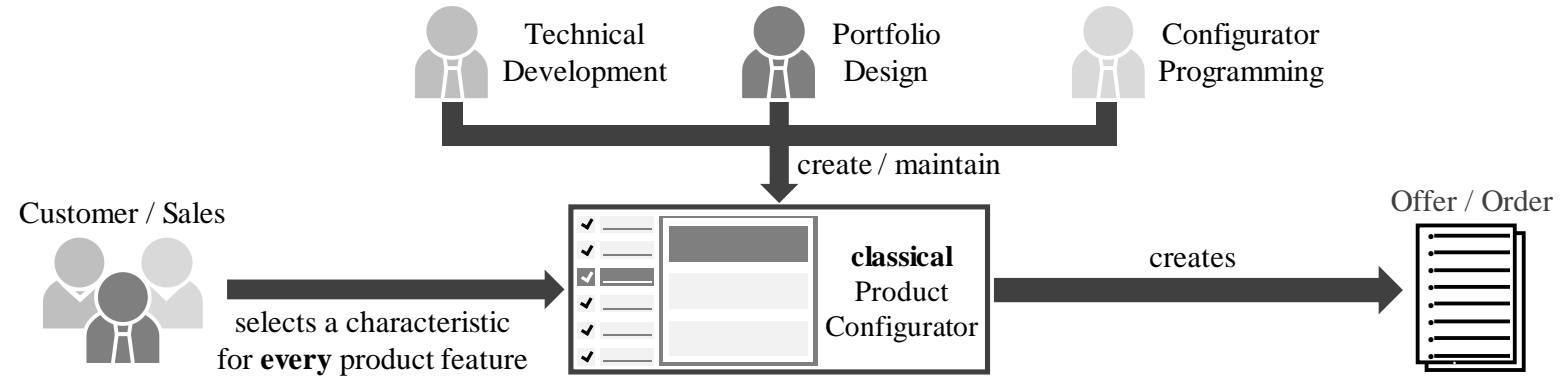

Figure 1. Procedure and role distribution of classical product configuration 
Model Based Systems Engineering (MBSE) represents a promising approach to overcome the tension between extensive individual customer requirements and the efficient design of a high variety product portfolio (Katzwinkel et al., 2018). By creating an interdisciplinary system model, all information arising in the development process are managed centrally (Deißenböck et al., 2010; Gausemeier et al., 2013). Even though the application of MBSE in the product development process is currently the subject of intensive research, its use in the industry has not been widely spread so far (Eigner et al., 2017; Grundel et al., 2014). Beyond that, there is currently no consideration of high variety product portfolios within MBSE, despite the claim to a complete product description (Weilkiens, 2011).

In contrast to the static rule-based dependencies of the traditional variant management, the model based configuration approach takes target quantities into account. As a result, only the product features with a high priority to the customer have to be determined. In addition, the user defines target quantities of his product variant like a cost limit or the maximal weight. Based on this data, the configurator identifies the optimal product variant by determining the non-differentiating featureoptions automatically. So, the more detailed consideration of requirements improves the creation of flexible customer-specific product variants and simultaneously helps to standardize product variants.

\section{State of the art}

Manufacturers who are able to offer customized technical solutions in an economic way, generate competitive advantages. According to a study by the Laboratory for Machine Tools and Production Engineering (WZL) of the RWTH Aachen University, more and more companies structure their product portfolios into modular product systems, due to the demand for mass customization products. Almost a quarter of the companies declared, that they are already using an implemented modular product system and another $40 \%$ are within the introductory phase (Arnoscht et al., 2010). In a modular product system, components and modules are combined as standardized units. A fixed set of configuration rules can be used to implement various overall functions by combining the modules (Borowski, 1961). This enables the configuration of almost individual products, while simultaneously exploiting economies of scale and learning effects (Arnoscht et al., 2010). With an orientation in line with the market and efficient design, development and manufacturing costs in industrial practice can be reduced by up to $20 \%$ (Schuh \& Co. GmbH, 2011). However, the arrangement of a product portfolio in a modular approach requires the initial development of a modular product structure as a basis (Feldhusen and Grote, 2013).

\subsection{Modular product architecture - The basis of a modular product system}

Technical systems can be analysed and described by different relationship dimensions (Göpfert, 1998). The most widespread approach is the product architecture. On the one hand, it describes the functional structure by breaking down the overall function into sub-functions and shows on the other hand the concrete physical implementation through components and assemblies in the product structure. Thus, at the lowest level the product architecture defines which components realize the specific sub functions (Feldhusen and Grote, 2013). Depending on the structure of the functional and physical relationships of the elements, the product architecture has an integral or modular character, as defined in the following (Feldhusen and Grote, 2013; Göpfert, 1998):

- Integral product architectures: Integral product architectures are characterized by a high functional and physical dependency of the components (view Figure 2). The dependencies result from the implementation of several functions through one component. Due to this highly cross-linked structure, the exchange and reusability of components is hardly possible (Feldhusen and Grote, 2013). This makes it difficult to control the complexity of integral design. By taking product features and characteristics into account, these product architectures however become manageable, because the functional independence can be increased (Konrad et al., 2017).

- Modular product architectures: The idea of modularization consists in dividing the overall complexity of the product. According to the modular principle, functionally and physically independent units (modules) can be combined by clearly defined interfaces. (Göpfert, 1998) 


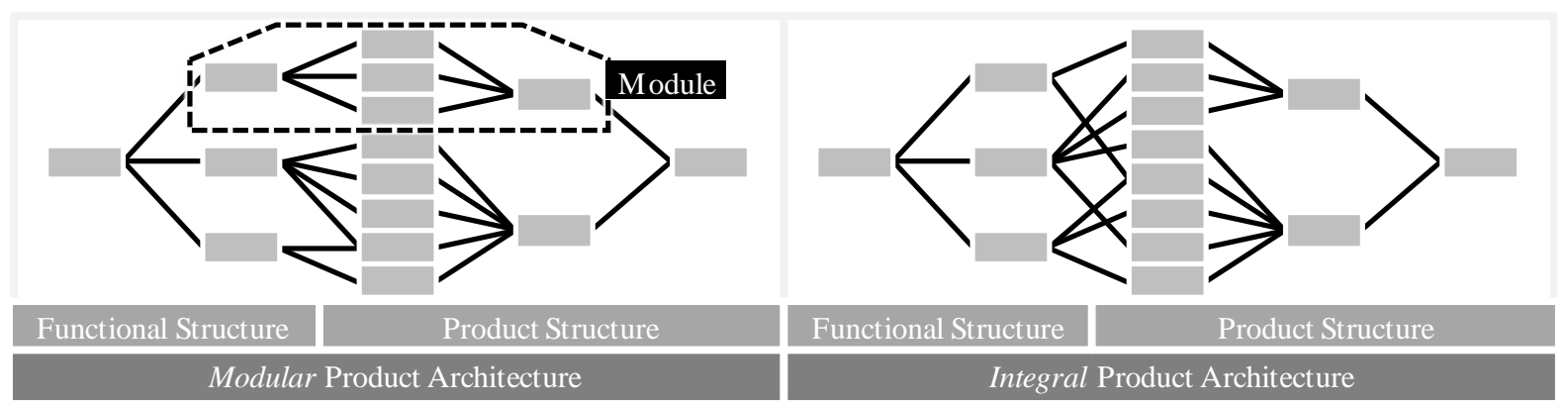

Figure 2. Integral and modular product architecture

\subsection{Configuration and compatibility matrices}

The configuration and compatibility matrices represent a proven approach for the description of the functional and technical relationships within a high variety product portfolio (view Figure 3):

- Configuration matrix: The configuration matrix defines the functional characteristics of all components of the modular product system. Thus, the available components for the configuration of a product variant are displayed within the matrix. (Feldhusen and Grote, 2013)

- Compatibility matrix: The combination of all components with each other represents the theoretical variety of the modular product system. However, from a technical as well as an economical point of view, not every combination of elements is reasonable. The compatibility matrix defines rules for the possible combinations of the available components. Depending on whether the functional and technical dependencies are defined within a matrix or separately, one or two compatibility matrices are used (Feldhusen and Grote, 2013; Puls, 2003).

\section{Configuration Matrix \\ "Which components are available in \\ the modular product systems?"}

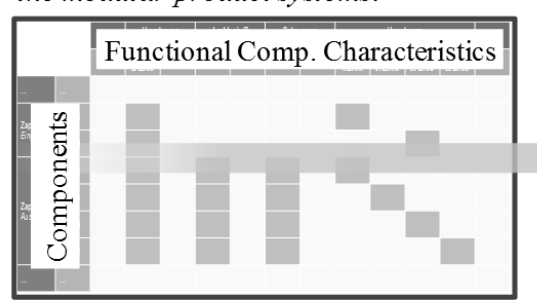

2. Compatibility Matrix

"Which components can be combined?"

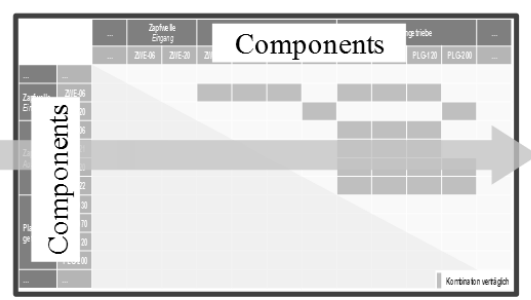

\section{Product Variants \\ "Which product variants can be created?"}

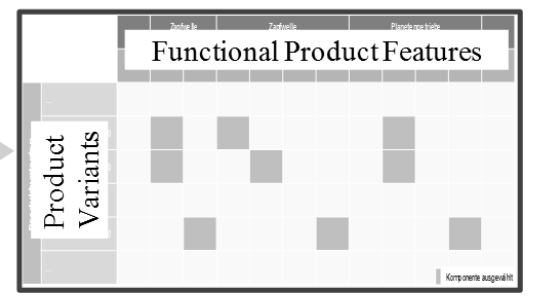

Figure 3. The concept of the configuration and compatibility matrices

Based on this general content, there exist different approaches to use the described matrices. Hellenbrands Extended Compatibility Matrix for example can support engineers in the selection of a consistent overall product concept in early design phases (Hellenbrand and Lindemann, 2008). Likewise, to be able to make decisions within early design steps, Jankovic develops the Multiple-Domain Design Scorecards to investigate the influence of interfaces on the global product architecture (Jankovic et al., 2012).

\section{Need for action and potential}

The use of traditional product configurators is widespread. A graphical user interface (GUI) enables the customer to generate an individual product variant from a modular product system and the sales department to calculate offers (view Figure 1) (Brinkop, 2019; Stormer, 2007). Despite this support, traditional product configurators are not suitable without restrictions for the industrial management of high variety product portfolios (Puls, 2003). The primal challenges of using today's product configurators are summarized in the following. These aspects represent the need for action for the revision of classical variant management approaches. In addition, a model based hypothesis for improvement is derived from each challenge:

1. Supply bottlenecks, model changes or changed market requirements demand the re-adaption of a modular product system. However, product configurators are often developed and used as stand- 
alone applications (Felfering et al., 2002). As a result, the stored configuration knowledge and the amount of components of the modular product system can often only be extended by great effort. Current configurators are therefore only inadequately suited for the long-term management of design and configuration knowledge (Männistö et al., 2001; Tiihonen et al., 1996). When there are changes in information, the configurator is obsolete. In addition, useful configuration knowledge is often documented across several departments and management systems (Riesener, 2015). Current solutions do not provide a way to use this information by a direct linkage. As a result, the process to a completely configured variant is often only partially transparent. This circumstance can be reinforced as the configurator is developed by software developers, whereas the modular product system is defined by engineers (Männistö et al., 2001; Tiihonen et al., 1996). Hypothesis for model based improvement: The application of MBSE changes the modelling environment of the product configuration.

2. The selection of the possible product options is often limited to a step by step procedure, until a product variant is completely defined (Abbasi et al., 2013). When using an interactive product configurator, the sequence for selecting the feature characteristics can be varied and adapted to the specific prioritised requirements of the user (Schneeweiss and Hofstedt, 2013). But, because traditional configurators are based on a static set of configuration rules, sufficient product features have to be defined to choose a specific pre-planned product variant. However, according to Tiihonen, up to $80 \%$ of the customer requirements which are supplied by the sales department, are incomplete or inconsistent (Tiihonen et al., 1996). A reason for this is, that not every selectable option portrays a differentiating feature for the customer. In addition, this description of the product configuration as a routine task with limited elements, does not allow a flexible adaptation of modules to customer requirements. (Männistö et al., 2001; Tiihonen et al., 1996) Hypothesis for model based improvement: The model based configuration extends the solution space of customer-specific product variants.

3. Within traditional approaches, the description of the configuration rules and the technical development of the modular elements are largely separated from each other. Physical effects or simulation results of a component are not directly linked to the creation of a product variant. Thus, the configurator is not linked to the digitally depicted product (Günter and Kühn, 1999; Männistö et al., 2001). As a result, information that is basically available, has to be attached separately (Tiihonen et al., 1996). Hypothesis for model based improvement: The system model connects information of domain-specific development tools to the configuration process.

\section{Solution approach}

In the following, these hypothesises for the model based improvement of the configuration of high variety product portfolios will be explained and evaluated based on a use case. Figure 4 summarizes the basic idea and the steps from the users input up to a completely determined product variant.

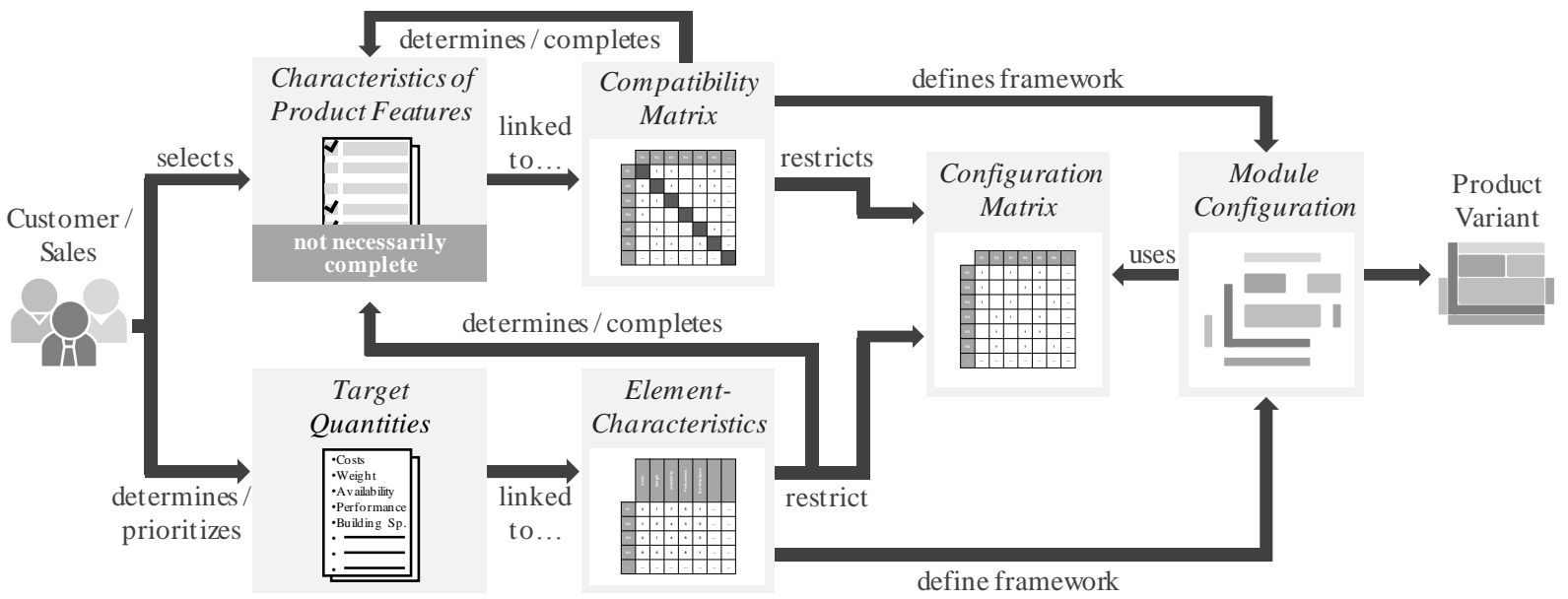

Figure 4. Concept and process of the model based product configuration 


\subsection{Case study - Research project eLVG}

The use case is located in the division of mobile machinery, as tractors for example. With the power take-off (PTO) tractors provide an interface for the transmission of mechanical energy to the working device. However, this connection is tied to the combustion engine with a fixed gear ratio, which limits the setting of an optimal operation point of the PTO. Within the research project $e L V G$ (German acronym for "electrically power split gearbox") a retrofit module was developed, that enables the variable adjustment of speed of the PTO-shaft of agricultural tractors (view Figure 5). The eLVG is created as a modular product system, to be able to adapt the power-split transmission to user requirements and thus make it accessible to a wide market. The modular product system of the eLVG application consists of the eight modules shown in Figure 5. Within the project, one configuration of the eLVG has been produced as a prototype. During subsequent and ongoing field tests, the functionality of the product design and the configurator have so far been positively evaluated (Gentz et al., 2018)

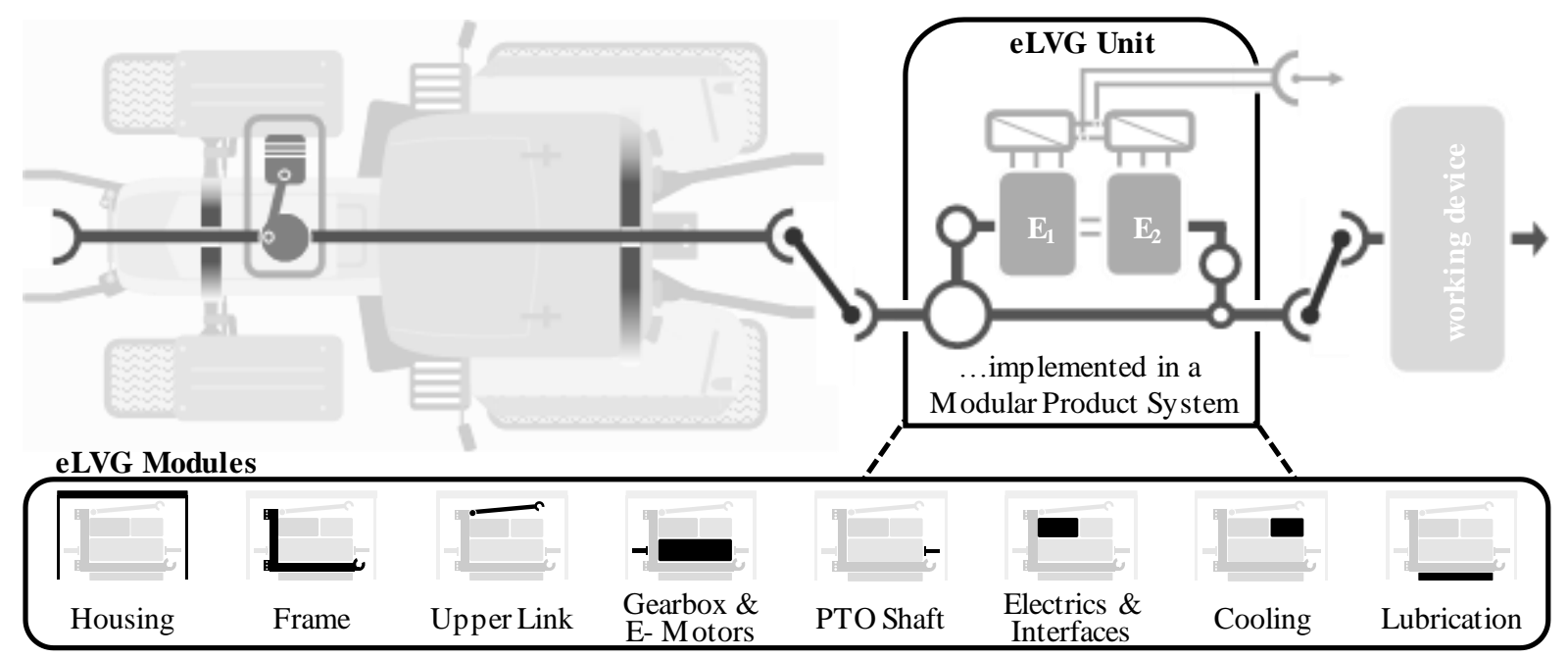

Figure 5. Research project eLVG

\section{eLVG product configurator}

The modular product system of the eLVG has been implemented in a configurator which can be operated by the GUI shown in Figure 6. Thereby the customer can select his preferred options for eight product features. These product characteristics are linked to each other by compatibility matrix. As a result, the decision for a characteristic may result in an automatic definition of additional options. However, the product configuration sequence is not predefined and can therefore be varied individually. In addition to the product features that can be selected by the customer, target quantities for the product variant can be defined. In this example, the maximal manufacturing costs and the desired delivery time are considered. Moreover, the desired properties can be prioritized against each other by using a slide control. The initial setting consists of the balanced consideration of both target quantities.

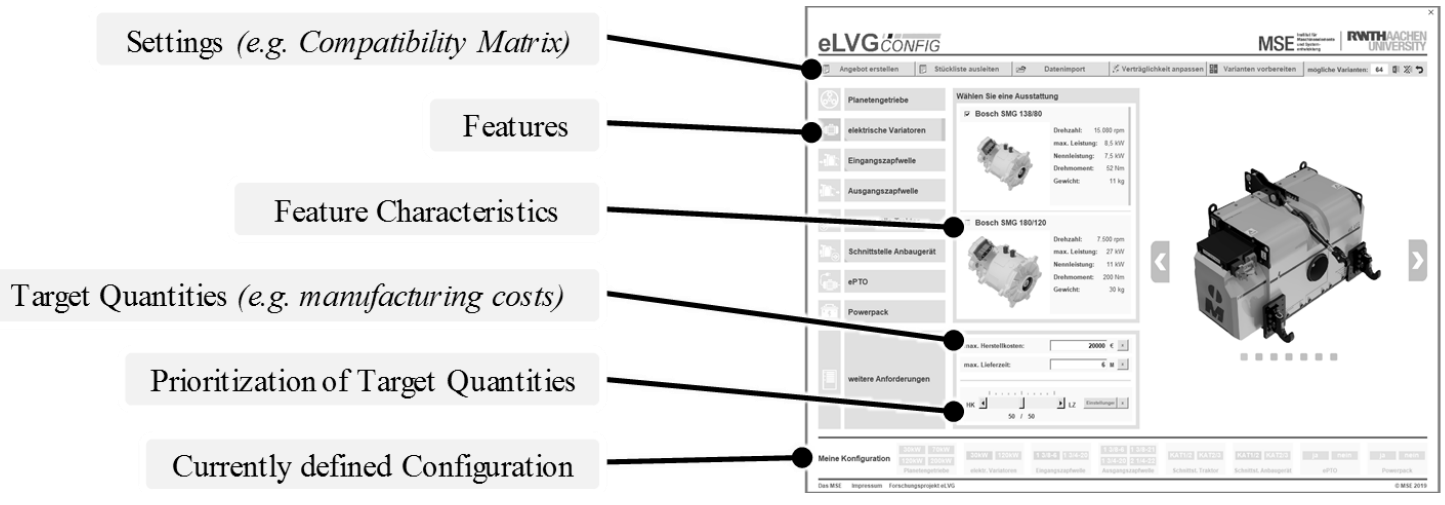

Figure 6. GUI of the eLVG product configurator 


\subsection{The application of MBSE changes the modelling environment of the product configuration}

Traditional product configurators are computer-aided systems (Brinkop, 2019) which help the user to satisfy the configuration rules. A configurator can be especially programmed with a custom configuration software (Brinkop, 2019). Thus, the configuration process can become non-transparent, because a technical engineer cannot implement a part into the software application, without programming experience. This divide between technic and software can be overcome by the change of the modelling environment from program code to a system model.

The system model supports the entire development process through a formalized visualization. As a result, the complexity and dependencies within a modular product system become traceable and decisive complexity drivers can be identified. The system model represents the Single Source of Truth (SSOT) for a product portfolio. This central storage and management of knowledge ensures the crosscompany use of the same information by every employee. So, the system model enables the adaptability and maintenance of the modular product system, prevents media breaks within the development and configuration process and allows the sustainable modelling of the configuration knowledge. As a result, this paradigm prevents cost-intensive overlaps and duplications.

Figure 7 shows the product structure of the eLVG in a model based approach up to the level of modules which are described within Figure 5. The module cooling is considered in particular.

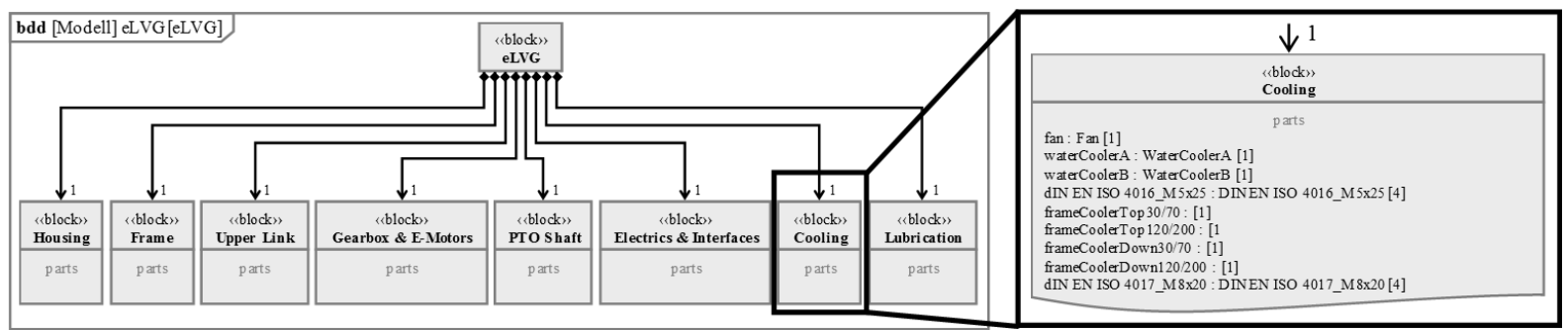

Figure 7. Model based eLVG product structure and module cooling

\subsection{The model based configuration extends the solution space of customer- specific product variants}

Customers view a product in a different way than the engineers designing it. Whereas customers are interested in the functions a product should fulfil, engineers are interested in technical solutions which implement them (Männistö et al., 2001). Then again the functions are described by product features and presented to the user by the GUI of a configurator. The customer selects the product features that are of decisive importance for the functional fulfilment of his product variant. However, when using a traditional configurator every product feature has to be defined, regardless whether the user pays attention to those characteristics or not. This need to define all options, can limit the variety of solutions significantly, although this would not be necessary.

The change of the modelling environment offers the possibility to reopen the solution space of product configuration. This is possible, because the system model contains the component properties, requirements as well as the component dependencies (view Figure 8) and combines them. The meaning of these values and their potential in terms of product configuration is described in the following:

- Component Properties: Each component of the modular product system contains a set of properties. Some of those values, like the manufacturing costs, the delivery time or the weight, are always attached. Other properties depend on the regarded component. For example, the RPM and torque are important for an electric motor, whereas they are not for a heat exchanger.

- Requirements: Requirements are constraints which have to be satisfied in order for components to be used for a task. So, a coolant pump can only be installed, when it can provide the required volume flow rate.

- Compatibility Matrix: The compatibility matrix defines which components can be combined with each other according to technical as well as economical views. The use of a hydraulic hose for example makes no sense, if an electrical motor has to be connected. 

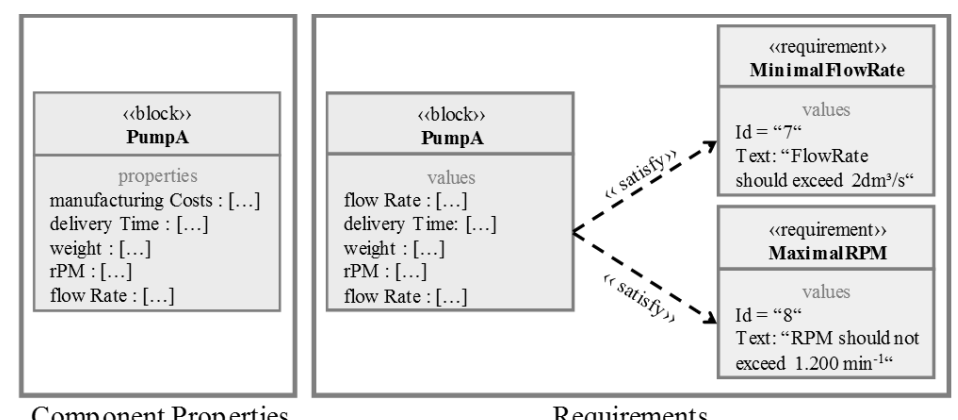

Requirements

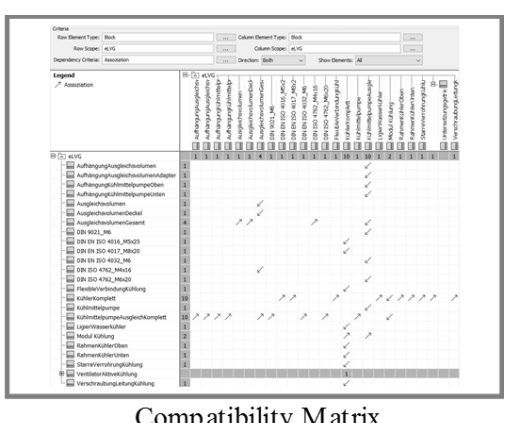

Compatibility Matrix

Figure 8. Model based component properties, requirements and compatibility matrix

The previously mentioned values allow, that the characteristics which are only of minor relevance to the customer, do not necessarily have to be defined by selecting a characteristic. Finally, however, the optimal product variant should be configured. In order to be able to restrict the solution variety of the theoretically possible product variants again, target quantities and streamlining functions are queried within the configuration process. Exemplary, these can be the maximal manufacturing costs or a weight limit. The configurator has access to the system model in which the information shown in Figure 8 is stored. In addition, the information can be prioritized by the customer. Thereby, a customer could have defined a cost limit and prioritize this accordingly over a short delivery time.

Along with the product features defined through the GUI and these target quantities, the most suitable product variant can not only be identified but especially generated by the use of multi-criterial optimization algorithms. The combination of extensive requirement structures and a diverse technical system represent a complex optimization problem. Genetic algorithms (GA) are the most commonly proposed approach to solve multi-criterial combinatorial problems (Simpson, 2004; as cited in Jiao et al., 2007). Through the simultaneous investigation of several locations of the solving space, GAs achieve valid solutions faster than conventional procedures, as unnecessary iterations can be dispensed with.

As a result, the modular product system makes it possible to standardize those components that do not represent a differentiating feature for the product user (Feldhusen and Grote, 2013). In addition, the modules can be configured to different variants themselves and adapted to customer requirements. Figure 9 shows the layout and principle configuration of the eLVG cooling module.

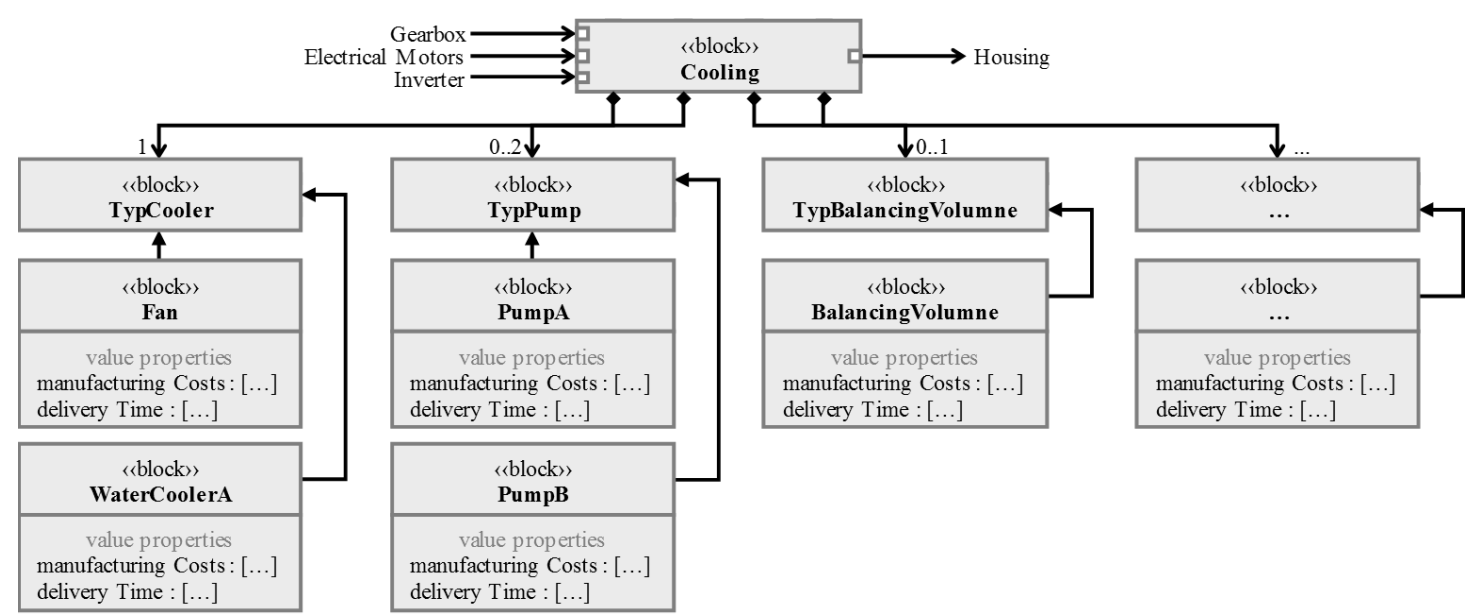

Figure 9. Model based dependencies and configuration of the module cooling

The cooling module cannot directly be influenced by the user's choice of product features, but has to be designed under consideration of the heat to be dissipated. The decisive factors are the gearbox, the electrical motors and the inverters. At the same time, the implemented cooling influences the selection of the housing components by the required installation space. In addition, the target quantities like the maximum manufacturing costs have to be satisfied. For the cooling module, this means for example, that a decision is made, whether the use of an air cooling or a water cooling system is necessary. If the amount of heat requires the use of a water cooler, a coolant pump is identified which can provide the 
necessary volume flow. It is also possible for the configurator to select two smaller pumps, which provide the required performance value in combination. Thus, each module represents its own submodular product platform.

\subsection{The system model connects information of domain-specific development tools to the configuration process}

A comprehensive system model offers the opportunity to link the information of domain-specific tools to the configuration process and generate even more data, by the use of calculation models. By doing so, development and simulation results can form the technical assurance of a product variant and enable a more flexible design of the module variants at the same time.

Within this paper the calculation model to estimate the manufacturing costs of a eLVG-Variant shall be used as an example (view Figure 10). During the configuration process, the cost model is updated with each executed step. Thus, the target quantities defined by the customer can be fulfilled.

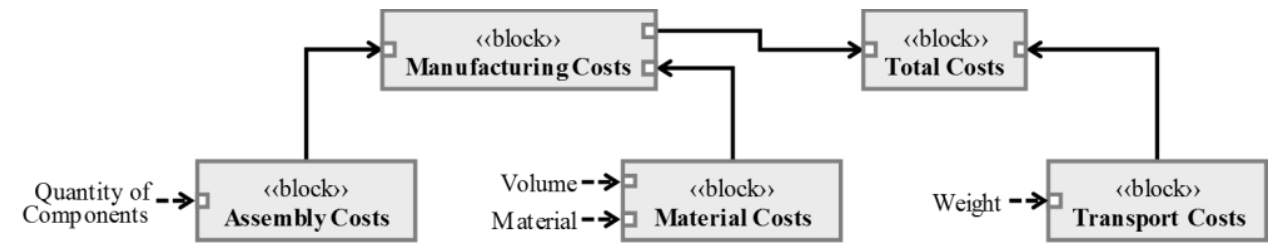

Figure 10. Cost model

\section{Application of the model based product configuration}

In the following, the model based configuration will be demonstrated for a product variant of the eLVG. Figure 11 summarizes the eight product features and their respective characteristics as well as the steps up to the complete configuration. Moreover, these selection-steps (1.-4.) are described below Figure 11.

1. Selection by Customer 2. Selection by Dependencies (defined by: Compatability Matrix)

3. Selection by Customer Selection by Restrictions and Prioritisation (Input by Customer, selected by Configurator)

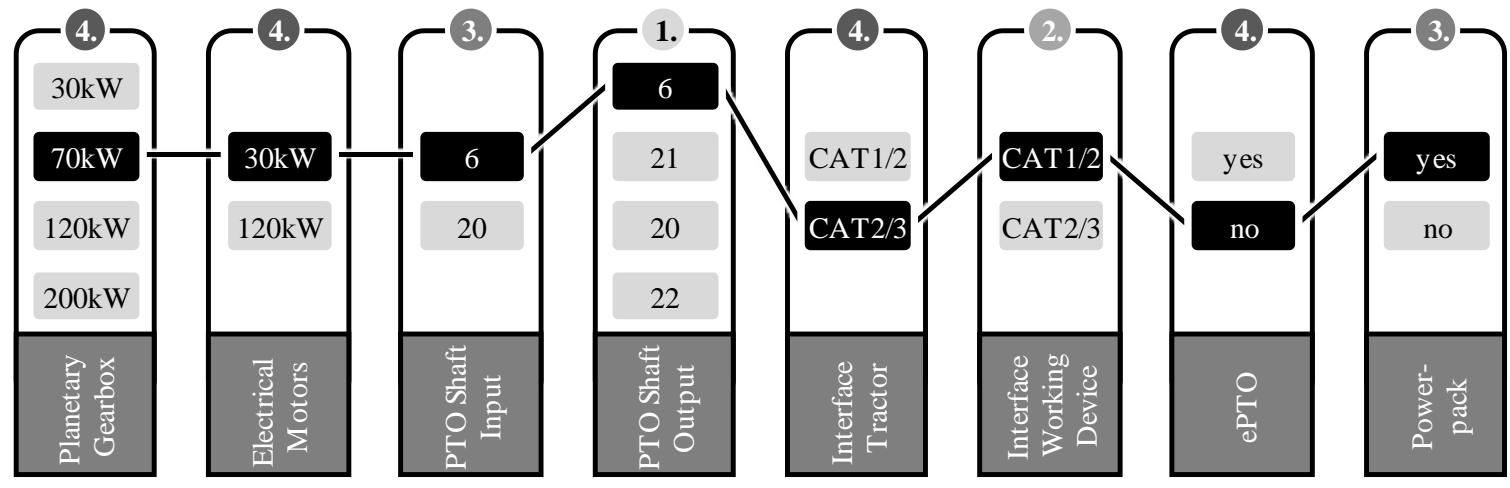

Figure 11. Exemplary configuration steps up to a complete product variant

1. Selection by Customer: The customer uses the configurator to select the output PTO shaft that matches his working devices.

2. Selection by Dependencies: The interface to the working device is automatically defined by the dependencies stored in the compatibility matrix. This configuration rule was determined on the basis of a market research conducted by the company.

3. Selection by Customer: The input PTO shaft is also a differentiating feature for the customer, as it has to be compatible with his tractor. At the same time, the customer wants to be able to use the eLVG as a so-called Powerpack (electrically operated emergency generator) and adds this functionality to his product variant.

4. Selection by Restrictions and Prioritisation: At this point, four of the eight product features have not yet been selected. The selection of a variant of the tractor interface is not relevant for the customer, since his tractor provides both options. However, a cost limit and a desired delivery 
date are defined. Due to approaching work in the field, a short delivery time is even more important to the customer than the price limit. With regarding these weighted restrictions, the algorithm determines that the ePTO function (electrical PTO) and the CAT1/2 as the tractor's interface exceed the desired delivery time. Due to the prioritization of the delivery time, the price limit will be exhausted. The configurator completes the functionally optimal product variant on this basis with a specification for the planetary gearbox and electrical motors.

\section{Summary and outlook}

The systematic and market-driven development of diverse product portfolios has become a key factor for successful companies (Feldhusen and Grote, 2013). One approach is to structure the portfolio in a modular product system, which is often used through a product configurator. Traditional configurators however are in many cases no longer suitable for the management of complex technical systems.

The model based product configurator extends traditional approaches of variant management, like the compatibility matrices, by using knowledge of the product development process and prioritized user target quantities in combination with multi-criteria optimization. Due to this continuous linking of customer requirements, modules can be used much more flexible, while complying the configuration rules at the same time. In addition, product features that do not portray a differentiating characteristic to the customer, do not have to be determined. The model based configurator identifies the most suitable product variant automatically by target quantities and optimization algorithms. Using the real example of the eLVG the configurator has been developed and implemented, including a GUI. By building a functional prototype of a configured product variant, the functionality of the method has been verified. Further potential lies in building a comprehensive system model and linking the MBSE software tools (so-called modeller) with domain-specific development tools. By integrating development results from CAD, FEM or MBS simulations, it is possible to link the product configuration with the stored calculation models.

With regard to the cooling module, this means that the amount of heat to be dissipated by the planetary gearbox does no longer have to be stored in the configurator in a separate way. The resulting heat is calculated by the system model and is taken into account as a boundary condition when dimensioning the cooling module. This integration makes it possible to adapt the configurator even more flexibly to changes in the components. Also the long-term management of configuration knowledge as well as the traceability of the creation of a product variant is increased. The combination rules stored in the compatibility matrix can thus be reduced. Dependencies between components and modules are described and graphically modelled by corresponding relationships within the integrated system model.

\section{References}

Abbasi, E.K. et al. (2013), "The Anatomy of a Sales Configurator: An Empirical Study of 111 Cases", In Advanced Information Systems Engineering, CAiSE 2013, Lecture Notes in Computer Science, held in Valencia, Springer, Berlin, Heidelberg, pp. 162-177. https://doi.org/10.1007/978-3-642-38709-8_11

Arnoscht, J. et al. (2010), "Effizienter innovieren mit Produktbaukästen: Studienergebnisse und Leitfaden - ein Beitrag zu Lean Innovation", http://publications.rwth-aachen.de/record/96865

Borowski, K.H. (1961), Das Baukastensystem in der Technik, 5. Bd., Springer, Berlin. https://doi.org/10.1007/9783-642-48735-4

Brinkop, A. (2019), Marktführer Produktkonfiguration, Brinkop Consulting, Vol. 39. Ausgabe, Available at: https://brinkop-consulting.com/guide/marktfuehrer.pdf

Deißenböck, F., Fritzsche, M. and Fernández, D.M. (2010), Wirtschaftlichkeit der modellbasierten Entwicklung: Workshop Hot-Spots der Software-Entwicklung, TU München. Available at: https://docplayer.org/1542 2778-Wirtschaftlichkeit-der-modellbasierten-entwicklung.html

Eigner, M., Koch, W. and Muggeo, C. (Eds.) (2017), Modellbasierter Entwicklungsprozess cybertronischer Systeme: Der PLM-unterstützte Referenzentwicklungsprozess der für Produkte und Produktionssysteme, Springer, Berlin. https://doi.org/10.1007/978-3-662-55124-0

Feldhusen, J. and Grote, K.-H. (Eds.) (2013), Pahl/Beitz Konstruktionslehre: Methoden und Anwendung erfolgreicher Produktentwicklung, Springer, Berlin, Heidelberg. https://doi.org/10.1007/978-3-642-29569-0

Felfering, A. et al. (2002), "Knowledge Acquisition for Buildung and Integrating Product Configurations", Collaborative Business Ecosystems and Virtual Enterprises, PRO-VE 2002, IFIP - The International 
Federation for Information Processing, Springer, Boston, Massachusetts, pp. 193-200. https://doi.org/ 10.1007/978-0-387-35585-6_21

Gausemeier, J. et al. (2013), "Studie: Systems Engineering in der industriellen Praxis", Tag des Systems Engineering, Stuttgart, Germany, November 6-8, 2013, Hanser Verlag, München, pp. 113-122. https://doi.org/10.3139/9783446439467

Gentz, C. et al. (2018), "Entwicklung eines elektrisch-leistungsverzweigten Anbaugeräteantriebs", Land.Technik 2018: das Forum für agrartechnische Innovationen, Leinfelden-Echterdingen, Germany, November, 12-13, 2018, VDI Verlag GmbH, Düsseldorf, pp. 205-2011. http://publications.rwth-aachen.de/record/766583

Göpfert, J. (1998), Modulare Produktentwicklung: Zur gemeinsamen Gestaltung von Technik und Organisation, Dissertation, Ludwig-Maximilians-Universität München, Gabler, Wiesbaden. https://doi.org/10.1007/978-3663-08152-4

Günter, A. and Kühn, C. (1999), "Knowledge-Based Configuration: Survey and Future Directions", XPS 99: Knowledge-Based Systems, Lecture Notes in Computer Science, Springer, Berlin, Heidelberg, pp. 47-66. https://doi.org/10.1007/10703016_3

Grundel, M. et al. (2014), "FAS4M - No more: 'Please mind the gap!'”, Tag des Systems Engineering, Bremen, Germany, November 12-14, 2014, pp. 63-74.

Hellenbrand, D. and Lindemann, U. (2008), "Using the DSM to support the Selection of Product Concepts", 10th International Design Structure Matrix Conference, Stockholm, Sweden, November 11-12, 2008, pp. 363-374.

Jankovic, M., Holley, V. and Yannou, B. (2012), "Muliple-Domain Scorecards: A method for architecture generation and evaluation through interface characterization", Journal of Engineering Design, Vol. 23, pp. 746-766. https://doi.org/10.1080/09544828.2012.706270

Jiao, J., Simpson, T.W. and Siddique, Z. (2007), "Product family design and platform-based product development: a state-of-the-art review", Journal of Intelligent Manufacturing, Vol. 18, pp. 5-29. https://doi.org/10.1007/s10845-007-0003-2

Katzwinkel, T. et al. (2018), "MBSE on parameter level”, NAFEMS18 DACH Conference Berechnung und Simulation: Anwendugen, Entwicklungen, Trends, Bamberg, Germany, May 14-16, 2018, pp. 129-132, http://publications.rwth-aachen.de/record/723965

Konrad, C. et al. (2017), "Varianzsteuerung integraler Produkte durch den prozessbegleitenden Einsatz von Data-Mining Werkzeugen", 15. Gemeinsames Kolloquium Konstruktionstechnik: Interdisziplinäre Produktentwicklung, Duisburg, Germany, October 5-6, 2017, pp. 213-222. http://doi.org/10.17185/ duepublico/44616

Männistö, T., Soininen, T. and Reijo, S. (2001), "Product Configuration View to Software Product Families", Helsinki University of Technology, Available at: http://www.soberit.tkk.fi/pdmg/papers/mannisto.pdf

Puls, C. (2003), "Die Konfigurations- und Verträglichkeitsmatrix als Beitrag zum Management von Konfigurationswissen in KMU”, VDI Verlag, Düsseldorf. https://doi.org/10.3929/ETHZ-A-004518023

Riesener, M. (2015), Ähnlichkeitsbasierte Produktkonfiguration im Maschinenbau, Dissertation, Apprimus Verlag, Aachen.

Schneeweiss, D. and Hofstedt, P. (2013), "FdConfiq: A Constraint-Based Interactive Product Configurator", In Applications of Declarative Programming and Knowledge Management, INAP 2011, WLP 2011, Lecture Notes in Computer Science, Springer, Berlin, Heidelberg. https://doi.org/10.1007/978-3-642-41524-1

Schuh, G., Arnoscht, J. and Nußbaum, C. (2007), "Produktarchitekturen richtig gestalten: ein Weg zum variantenoptimierten Produktprogramm", Industrie-Management: Zeitschrift für industrielle Geschäftsprozesse, pp. 29-32. http://publications.rwth-aachen.de/record/158901? 1 =de

Schuh and Co. GmbH (Eds.) (2011), Effektivität und Effizienz durch Produktbaukästen, Das Complexity Management Journal, Ausgabe 3/2011, Available at: https://schuh-group.com/site/assets/files/1561/cmjournal_3-2011_2016-03-31_esa_korr.pdf

Simpson, T.W. (2004), "Product platform design and customiziation: Status and promise", Artificial Intelligence for Engineering Design, Analysis and Manufacturing, Cambridge University Press, pp. 3-20. https://doi.org/ $10.1017 / \mathrm{S} 0890060404040028$

Stormer, H. (2007), "Kundenbasierte Produktkonfiguration”, Informatik Spektrum, Springer, pp. 322-326. https://doi.org/10.1007/s00287-007-0177-1

Tiihonen, J. et al. (1996), "State-of-the-practice in product configuration: A survey of 10 cases in the Finnish industry", Knowledge Intensive CAD, Chapman \& Hall, pp. 95-114.

Weilkiens, T. (2011), Systems Engineering with SySML/UML: Modeling, Analysis, Design, Elsevier 